\title{
Tumaco-Tolita: cultura, arte y poder en la costa pacífica
}

Diógenes Patiño C.

\section{RESUMEN}

A PARTIR de teorías Y MÉTOdos CONTEMPORÁNEOS, ESTE ARTíCUlO INTERPRETA LOS DESARROLLOS PREHISPÁNICOS en el sur de la costa Pacífica de Colombia, especialmente sobre los pueblos Tumaco-La Tolita, cuyos límites Se extendieron hasta el territorio aCtual de Esmeraldas en el Ecuador. Teniendo en cuenta LA TEORÍA Y DATOS ARQUEOLÓGICOS RECIENTES, SE INTENTA ANALIZAR LA IMPORTANCIA DE LA CULTURA, EL ARTE Y EL PODER DESDE DONDE SE INFIERE EL CARÁCTER CULTURAL, SOCIAL Y POLÍTICO DE ESTAS COMUNIDADES, QUE SE MUESTRAN COMO SOCIEDADES JERÁRQUICAS DOMINANDO UN AMPLIO TERRITORIO, QUE FUE EXPANDIDO Y EXPLOTADO DE TAL MANERA QUE SUS CONEXIONES Y REDES DE INTERCAMBIO ALCANZARON REGIONES COSTERAS E INTERANDINAS LEJANAS.

Palabras Claves: Arqueología - Tumaco-Tolita - cultura - arte - Poder - Costa Pacífica - Colombia-Ecuador.

\section{Abstract}

USING CONTEMPORARY THEORIES AND METHODS, THIS ARTICLE INTERPRETS PREHISPANIC DEVELOPMENTS ON THE southern Pacific coast of Colombia, especially the Tumaco-La Tolita pueblos whose limits extended to THE CURRENT TERRITORY OF ESMERALDAS IN ECUADOR. TAKING INTO ACCOUNT THEORY AND RECENT ARCHAEOLOGICAL DATA, WE ANALYZE THE IMPORTANCE OF CULTURE, ART AND POWER FROM WHICH THE CULTURAL, SOCIAL AND POLITICAL CHARACTER OF THESE COMMUNITIES SUGGESTS THAT THESE GROUPS WERE HIERARCHICAL SOCIETIES DOMINATING A WIDE TERRITORY, EXPANDING IT AND EXPLOITING IT IN SUCH A WAY THAT ITS CONNECTIONS AND EXCHANGE NETWORKS REACHED DISTANT COASTAL AND INTER-ANDEAN REGIONS.

Keywords: Archaeology - Tumaco-Tolita - Culture - Art - Power - Pacific Coast - Colombia-Ecuador.

* Profesor del Departamento de Antropología de la Universidad del Cauca, su maestría y doctorado lo obtuvo en Temple University, Philadelphia, USA. Su trabajo en arqueología se ha desarrollado principalmente en el sur de Colombia. Correo electrónico: diopatin@unicauca.edu.co. 


\section{Introducción}

$\mathrm{E}$ n esta sección se tratará de interpretar desde teorías y métodos contemporáneos los desarrollos prehispánicos en el sur de la costa Pacífica de Colombia, especialmente sobre los pueblos Tumaco-La Tolita, cuyos límites se extendieron hasta el territorio actual de Esmeraldas en el Ecuador. Se ha tratado de enfocar la cultura prehispánica desde varios aspectos relevantes, siendo el arte y el poder la base de la interpretación desde donde se infiere el carácter cultural, social y político de estas comunidades que se muestran como sociedades jerárquicas dominando un amplio territorio, expandiéndolo y explotándolo de tal manera que sus conexiones y redes de intercambio alcanzaron regiones costeras e interandinas lejanas. Teniendo en cuenta la teoría y datos arqueológicos recientes, se intenta analizar la importancia de la cultura, el arte y el poder en las sociedades Tumaco-Tolita, o también conocidos como Tulato, término contraído del original y acuñado por A. Brezzi en el 2003. Aquí el término se refiere a los cacicazgos de esta región costera.

\section{El paisaje natural costero: entre mar, esteros (manglar) y ríos (selva)}

La región sureña de la costa Pacífica de Colombia se caracteriza por una costa con llanuras planas fértiles de origen aluvial, por ella transitan abundantes ríos que nacen en la cordillera Occidental o incluso en la Central, como es el caso del río Patía que se abre paso por el sitio Hoz de Minamá; después de dejar las estribaciones andinas montañosas se llega a la llanura aluvial, una franja entre los 60 a $80 \mathrm{~km}$. de ancho, con relieve ondulado de origen cuaternario y algunos cerros del terciario, su vegetación aún contiene abundantes bosques de selva húmeda tropical, sobre todo en aquellas zonas alejadas de los centros urbanos costeros (Tumaco, Iscuandé, Guapi, Timbiquí y Buenaventura). Después de la llanura firme se determinan zonas ecológicas y ambientales con una alta influencia marítima, con mareas que pueden llegar hasta 8 metros tierra adentro, estas fluctuaciones crean nichos ecológicos en zonas denominadas natales, guandales, manglares y playones, áreas que se caracterizan por una extraordinaria biodiversidad tanto en recursos faunísticos como de la flora tropical. Las zonas bajas son naturalmente interconectadas a través de una intrincada red de esteros y canales que conectan el mar y la llanura aluvial por tributarios y ríos principales como el Mira, Mexicano, Caunapí, Rosario, entre otros (Láminas 1 y 2). Esta región sur costera del Pacífico fue la sede principal de extensos asentamientos de grupos humanos en diversas épocas; sin embargo, la mayor y más importante ocupación se dio en tiempos prehispánicos entre el 2.350 al 1.650 A. P., con las culturas que hoy conocemos como Tumaco-Tolita.

\section{La ocupación prehispánica y temporalidad en el pacífico costero}

Los estudios arqueológicos costeros en las llanuras aluviales al sur del Chocó son limitados teniendo en cuenta la gran extensión del territorio y su importancia durante los diferentes períodos de ocupación y su colindancia con la región altoandina. A pesar de este hecho podríamos trazar un mapa arqueológico general para la costa Pacífica sur. Las ocupaciones humanas más antiguas aparecen en territorio ecuatoriano, con una notable influencia de la cultura Chorrera del Ecuador, cuyas gentes conocían bien la pesca marina, las técnicas agrícolas y una avanzada destreza por la metalurgia y alfarería; al parecer esta influencia cultural entra a lo que hoy es territorio colombiano hacia el 2.800 A.P. con asentamientos en la llanura aluvial que dieron lugar posteriormente a transformaciones culturales y sociales importantes que desembocaron en las llamadas culturas Tumaco-La Tolita hacia el 2.350 A.P. Los Tumaco-Tolita fueron grupos humanos que alcanzaron desarrollos notables en sus aspectos políticos, sociales y económicos, no existe en la región, ni en el noroeste de Suramérica otra cultura que se parezca a esta y haya alcanzado tales desarrollos, bajo el dominio de importantes caciques y chamanes con altos poderes religiosos y políticos en las regiones costeras de Colombia y Ecuador. 

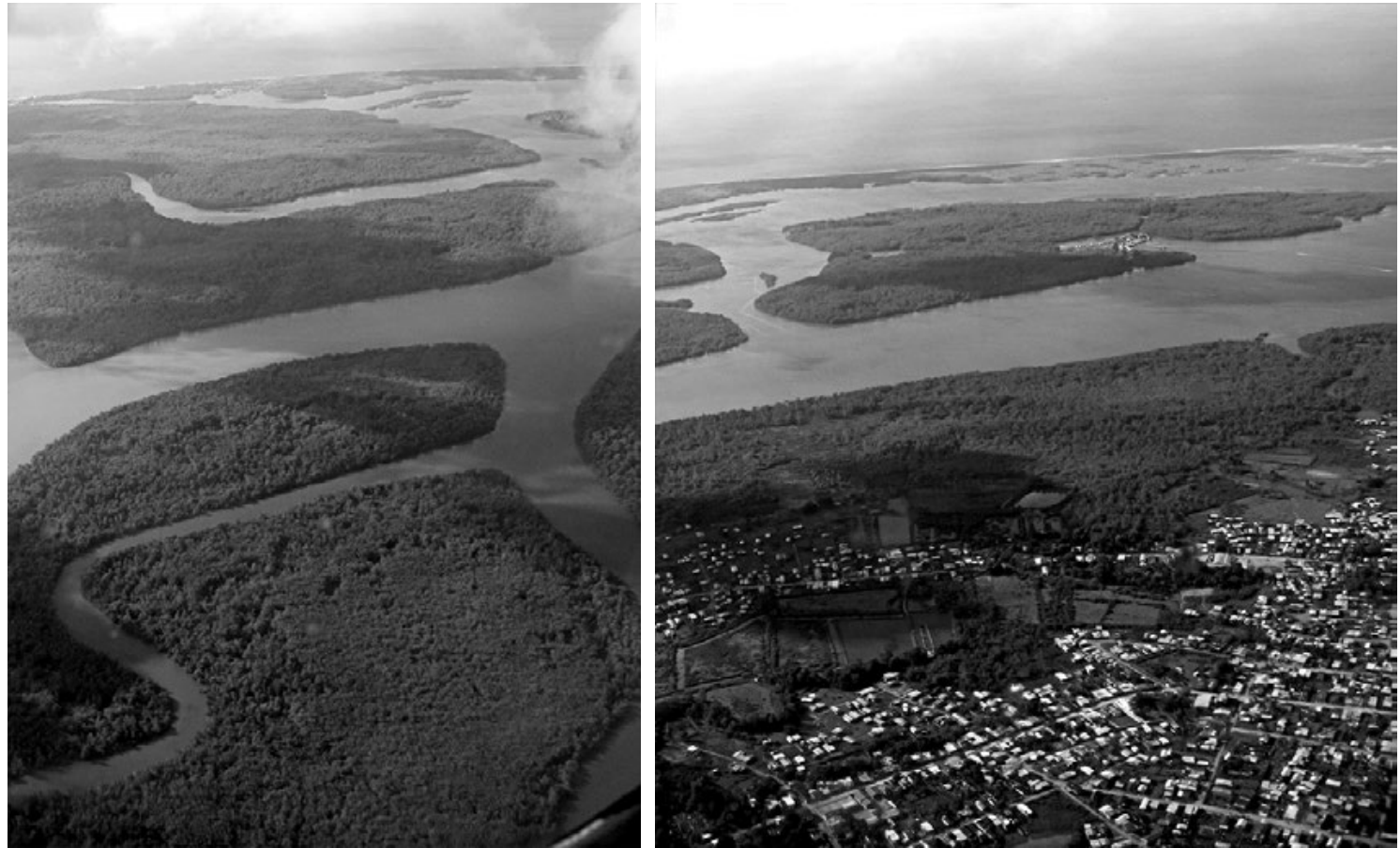

LÁminas 1 y 2. Tumaco. Esteros y Manglares. Foto: Diógenes Patiño.
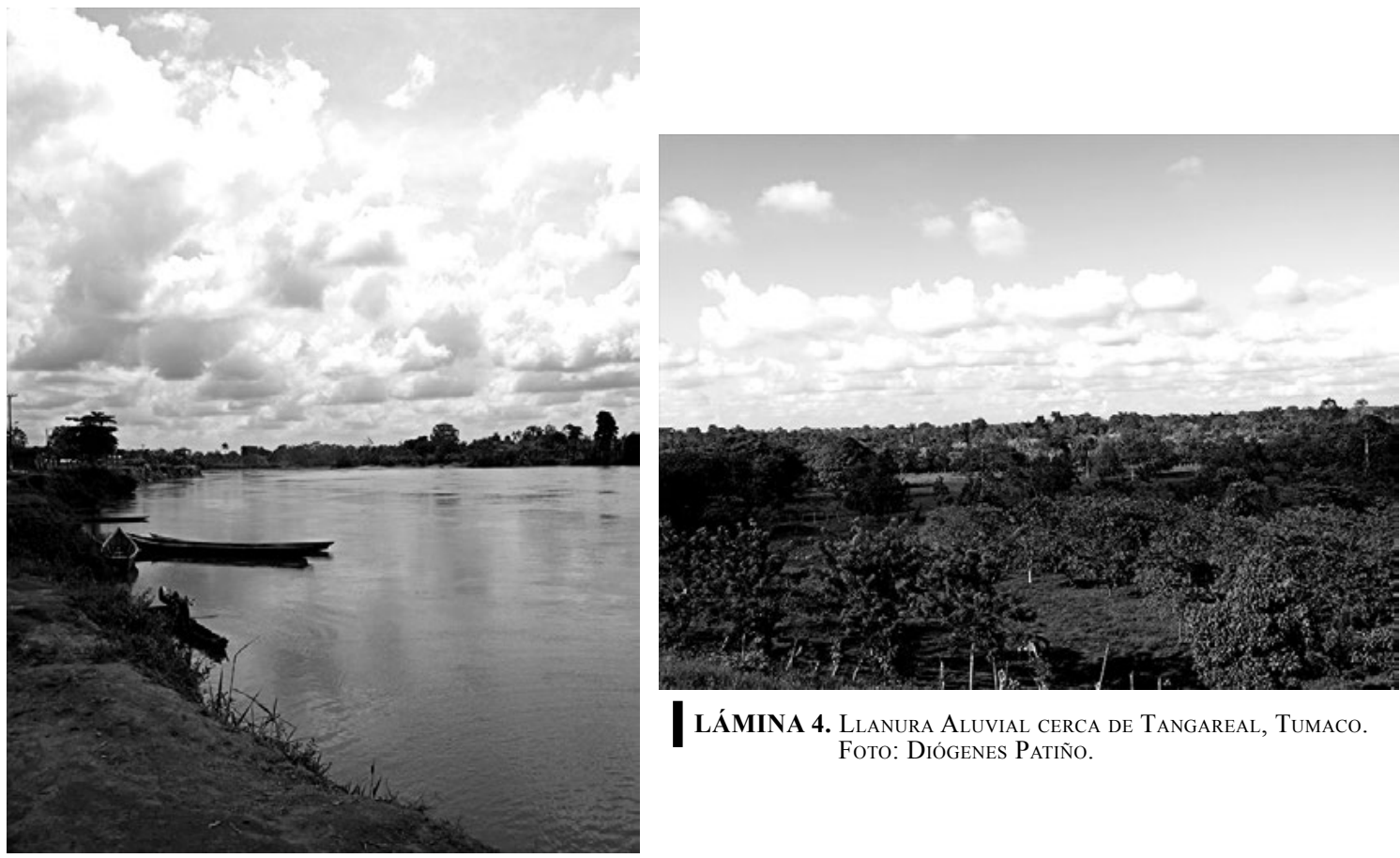

Lámina 4. Llanura Aluvial cerca de Tangareal, Tumaco. Foto: Diógenes PatiÑo.

LÁmina 3. Río Mira, Tumaco. Foto: Diógenes Patiño 
Las evidencias en la región también apuntan hacia una tesis migratoria desde áreas mesoamericanas, que pudieron fusionarse con culturas ya existentes bien sea durante el período Chorrera o épocas posteriores (Patiño, 2003). Esta tesis no ha sido investigada a fondo, sin embargo, las analogías arqueológicas en ambas regiones son sorprendentes y pudieron ser posibles gracias a migraciones causadas por el alto vulcanismo desarrollado en Centro América, especialmente en México, Guatemala, El Salvador y Costa Rica. Hacia épocas posteriores tardías se observan muchos grupos y asentamientos a lo largo de la costa y llanura del Pacífico colombiano, no obstante, sus estructuras políticas, sociales y económicas en nada se parecen a las culturas pasadas, sus vestigios se relacionan más bien con sociedades tropicales de las tierras bajas selváticas y del piedemonte andino, dirigidas al parecer por caciques o jefes muy locales, algunos encontrados al momento de la Conquista. Posteriormente, el Pacífico es ocupado por la colonización española que poco a poco fue dominando los territorios y sus comunidades para la explotación minera, especialmente en la provincia de Barbacoas (Nariño) y las extracciones de oro de aluvión y filón en el Cauca, Valle y Chocó, para lo cual se introdujeron grupos de africanos esclavos quienes de alguna manera suplieron la mano de obra indígena ya diezmada en las minas y haciendas coloniales (Siglos XVI-XVIII) (Barona, 2001; Romoli, 1963).

\section{Los cacicazgos y sus pueblos}

En la teoría sobre las culturas arqueológicas del suroccidente colombiano se ha pensado con suficientes motivos que sus desarrollos culturales tuvieron una notoria organización política, social y económica equivalente a lo que se conoce como cacicazgos. Estas sociedades se caracterizaron por tener poblaciones relativamente altas asentadas en pueblos y aldeas, ocupando amplios territorios, con un activo intercambio de diferentes productos llevados a corta y larga distancia. En las comunidades se destacan los especialistas en todo tipo de oficios, especialmente en orfebrería, alfarería y otros objetos que requieren dedicación y conocimiento tecnológico. En estas sociedades igual se cree que había un amplio control de excedentes para la redistribución en la población, construcción de obras de infraestructura y un próspero manejo de la agricultura basada en el maíz y otros productos, para implementar sus técnicas se requirió abundante mano de obra para construir camellones, eras y extensos canales de drenaje bajo un estricto mantenimiento de los mismos.

En las evidencias de cultura material se pueden rastrear la estructura social y de poder, especialmente a través de los bienes suntuarios y el arte de la arcilla y el metal, encontrados en tumbas, montículos y unidades residenciales. Se infiere que los miembros de la élite tuvieron los medios para adquirir objetos preferenciales (ejemplo, ornamentos orfebres, cuentas de collar en piedra, concha, hueso, entre otros), sirviendo a su vez como símbolos de estatus personal. Igualmente se percibe que la demanda de estos bienes estimuló la producción artesanal de especialistas y su intercambio a lo largo de extensas zonas andinas y costeras (Earle, 1991, 1997; Drennan, 1991; Patiño, 2003; Reichel-Dolmatoff, 1986). Estas posiciones teóricas cada vez más son respaldadas por nuevos hallazgos a través de estudios arqueológicos que se sirven de datos etnohistóricos, etnográficos y medioambientales para sustentar el tipo de culturas y su organización social, económica y política en el suroccidente colombiano (Cieza, 1976; Romoli, 1976). En la costa Pacífica de Colombia y Ecuador se encuentra esta forma de desarrollo cultural expresado en evidencias y hallazgos arqueológicos de las culturas Tumaco - La Tolita, una de las más importantes en el noroeste de Sur América. 


\section{Caciques, chamanes y poder en el Tulato: arte a través de la arcilla y el metal}

Con base en varios estudios arqueológicos regionales, se puede inferir que en Tumaco y La Tolita hubo importantes desarrollos culturales que podemos evidenciar como cacicazgos hegemónicos costeros, caracterizados por una unidad sociopolítica y económica compleja, que prosperó entre el 2.350 y 1.650 A.P. a lo largo de la costa Pacífica de Colombia y Ecuador (Bouchard y Usselmann, 2003; Patiño, 2003). Para esa época sociedades de rango dominaron un vasto territorio costero, donde se destacan poblados, cementerios en montículos, campos agrícolas y un importante desarrollo del arte y la cultura. Sus alcances no solo fueron locales, sino que también desarrollaron un amplio sistema de intercambio regional, especialmente marcado por las relaciones a corta y larga distancia dentro de un circuito que conectaba la costa, utilizando las mareas y esteros, la llanura aluvial plana y sus ríos, hasta alcanzar las tierras altas andinas de Ecuador y Colombia, donde se obtenían diversos productos exóticos como la obsidiana (vidrio volcánico) y otras materias primas.

Como se dijo, no cabe duda de que las evidencias arqueológicas sobre las sociedades del Tulato indican una compleja división política y social al interior de sus pueblos. Este aspecto se ha observado, por un lado, en las excavaciones de montículos habitacionales y funerarios con variación en las formas de enterramiento y ajuares; por otro, en el arte plástico en metales (oro, platino y tumbaga) y cientos y cientos de figurillas antropomorfas de barro cocido, dejadas casi como retratos (imágenes realistas) de las gentes que vivieron e interactuaron en la región costera. Estos materiales han sido ampliamente difundidos en la literatura arqueológica y a través de museos y colecciones del arte prehispánico en América y Europa (Brezzi, 2003; Bouchard y Usellmann, 2003; Cubillos, 1955; Duncan, 1994; Errázuriz, 1980; Ugalde, 2009; Valdez, 1987).

Los estudios de la simbología etnológica de la plástica, la estética, la iconografía y las representaciones escénicas que resultan de las actividades culturales, son importantes para definir el arte de una cultura como expresión del sistema de valores que la rigen. En TumacoTolita desde la perspectiva del arte plástico podemos distinguir dos elementos importantes de análisis, ambos se refieren a pensar las ideas iniciales que motivaron a sus artistas, para: (1) representar simbólicamente un hecho, una costumbre o un ritual y, (2) realizar obras cuya figura central es la representación humana para plasmar las imágenes de personas (retratos), escenas de la vida real y la cotidianidad (los ciclos de la vida y la condición humana). La realización de figuras humanas no solo obedece al impulso de imitar la imagen de la figura corpórea, sino que corresponde al deseo de que esa pieza artística cumpla con una función simbólica asociada al sistema cultural y social imperante (Di Capua, 2002). Las representaciones figurativas, en sí mismas, son portadoras de mensajes codificados que pueden ser descifrados a partir de análisis semióticos para acercarnos a las ideas originales de sus artífices y lo que representan para la estructura social, económica y política de una sociedad (Ugalde, 2009). Para M. Elíade, lo simbólico es ante todo una realidad remitente, porque no representa algo en sí mismo, sino que plantea una fuerte relación entre lo que significa y la realidad pasada, revela la dimensión real pero a la vez ésta no es inmediata (Elíade, 1974).

Teniendo en cuanta lo anterior, ambas concepciones de la imagen y su función simbólica están presentes en el arte figurativo plástico de los Tulato, expresadas especialmente en el arte de la arcilla y los metales; así, es posible interpretar el significado de la figura humana, su contexto social y simbólico dentro de los espacios de esta comunidad arqueológica. Existe en esta cultura una obsesión por la figura humana (retrato) recargada de mucha simbología, hasta el punto de pensarse que nos encontramos ante personajes que tuvieron dimensiones reales en el pasado, lo que nos lleva a inferir la presencia de gentes de diversa estirpe e investidura como caciques, chamanes, guerreros, comerciantes, artesanos y gentes comunes de pescadores y agricultores. Como diría Ugalde, los objetos figurativos de estas culturas nos llevarían a la reconstrucción de una sociedad compleja con una notable ajetreada vida política (Ugalde, 2009). 


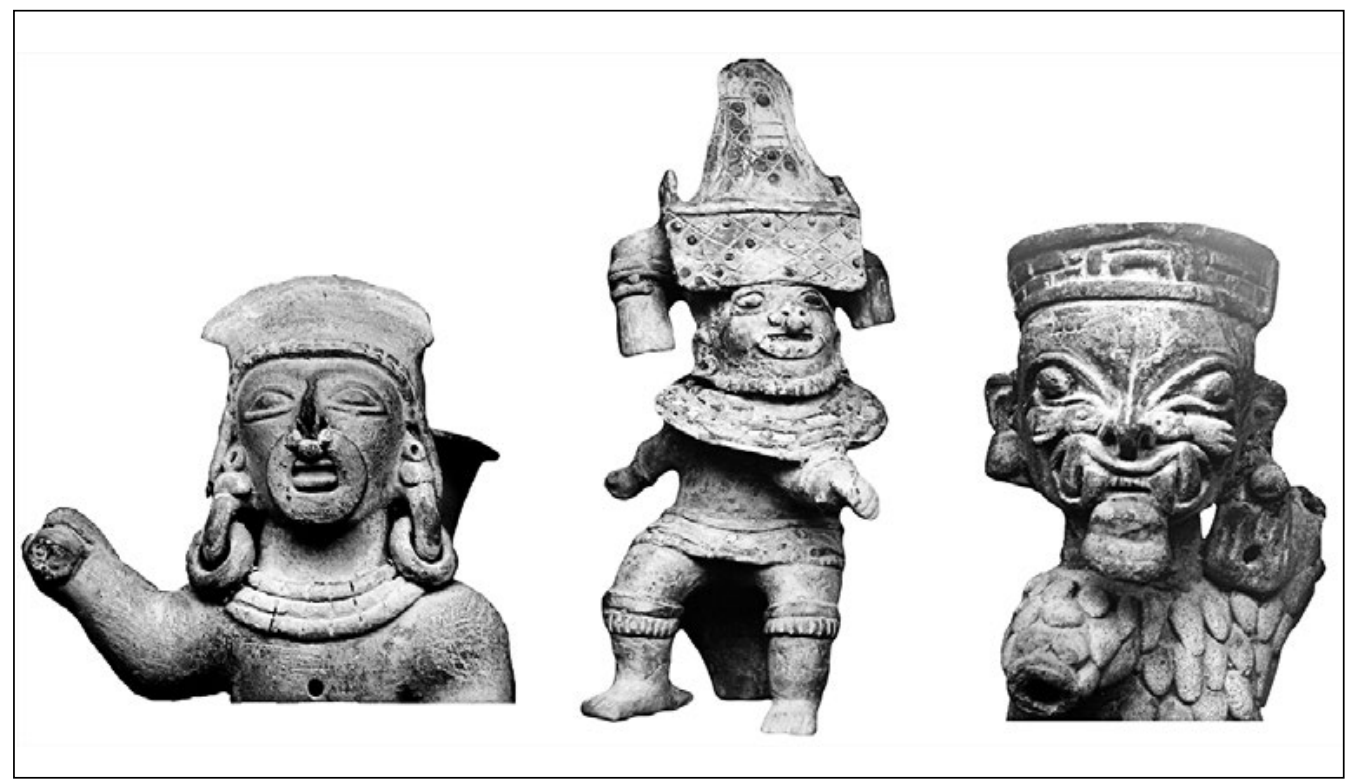

LÁmina 5. Personajes Tulato, “Caciques" y “Chaman" (Jaguar-emplumado). Casa de la Cultura, Tumaco; U. Nacional.

En Tumaco existe una estrecha relación entre los personajes de rango y el uso de objetos suntuarios, como adornos y piezas de oro, platino y tumbaga, las cuales fueron manufacturadas por especialistas orfebres quienes atendían las demandas y necesidades de una sociedad en pleno apogeo. Varios autores han sugerido para este tipo de sociedades la presencia de especialistas adscritos, bien sea a las élites o a las instituciones de poder, con ello se garantizaba, a través del intercambio, los elementos básicos que se requerían para los trabajos artesanales, así los trabajos de los especialistas se convierten en artesanos importantes para las artes del barro, orfebrería, concha y hueso. Las demandas de estos productos creadas por las estructuras sociales de poder influyen en los trabajos especializados y sus formas de intercambio regional, así mismo se mantiene a través de estos objetos el papel funcional de los elementos simbólicos, rituales y de poder (Brumfiel y Early, 1987; Feldman, 1987; ReichelDolmatoff, 1988).

En las sociedades del Tulato, el arte de la metalurgia aparece desde épocas tempranas hacia el 2.400 A.P., en sitios poblados con montículos, como La Magnolia (Chilví), localizado a $15 \mathrm{~km}$. de la costa, donde también se encuentra una extensa área de campos de cultivo prehispánicos de la región de Inguapí y Chilví (cerca del río Mira). Las piezas orfebres de láminas repujadas y alambres de oro se encontraron en suelos antropogénicos con alta concentración de material carbonizado, huellas de poste, figurillas humanas, fragmentos de vasijas y restos de conchas y peces. Estos rasgos en su conjunto sugieren áreas de actividad, donde labores artesanales como la orfebrería se desarrollaron.

Los avances en conocimientos técnicos dentro de esta cultura son muy variados, conocieron el laminado, repujado, granulado, dorado por oxidación, filigrana, uso de molde y fundición para adornos en serie, conglomerado por fusión, cera perdida, entre otras técnicas. No sólo trabajaron el oro, también hicieron piezas en plata, platino y tumbaga, para realizar piezas bimetálicas de alto contenido simbólico (Scott, 1991). El conocimiento de la orfebrería y la arcilla como expresión plástica y simbólica en el Tulato, fue tan importante que sus hallazgos se distribuyen en un amplio territorio costero desde Esmeraldas (Ecuador), Tumaco, Isla Gorgona, hasta Isla Soldado y Bocana en la Bahía de Buenaventura (Colombia). En esta vasta región se 
hallan en los mismos depósitos restos orfebres (láminas colgantes, botones, adornos en filigrana y desperdicios) asociados a materiales culturales de filiación Tumaco-Tolita (Patiño, 1988; Emmerich, 1984; Estévez, 1995; Scott y Bray, 1980: 153).

Scott en sus trabajos metalográficos resalta la destreza de estos orfebres, quienes hicieron desarrollos considerables en la metalurgia hasta llegar a controlar los puntos de fundición de diferentes tipos de aleaciones de oro (cf. 1980; 1988; Scott y Doehne, 1990). Entre los objetos manufacturados en metales se elaboraron adornos personales consistentes en clavos faciales, narigueras, aretes, pendientes, cuentas de collar, pezoneras, diademas e incrustaciones dentales. En algunos casos estos objetos forman conjuntos de ornamentos acompañados de piedras finas (e.g., jadeíta, turquesa, ágata y cuarzo). Varios de los objetos seguramente tuvieron un carácter chamánico ritual y se incluyen entre ellos cascabeles, mascarones con fauces de jaguar, pectorales antropomorfos y zoomorfos, figuras humanas ensambladas, como también figurillas en arcilla con adornos orfebres. Otros objetos corresponden a agujas, anzuelos y clavos usados para ensamblar piezas mayores. En la metalurgia Tumaco-Tolita no existen las grandes piezas de aves con alas desplegadas, pectorales acorazonados ni diademas en forma de "hache" que emulan un mundo chamánico complejo, especialmente en las sociedades andinas del suroccidente colombiano. Aunque la mayoría de las técnicas y algunas formas iconográficas de la metalurgia del suroccidente se comparten, la orfebrería Tumaco-Tolita forma un conjunto muy particular originado en las sociedades complejas costeras (Emmerich, 1984; Estévez, 1995; Fresco, 1995; Plazas y Falchetti, 1986; Reichel-Dolmatoff, 1988; Valdez, 1987; Zapater, 1995).

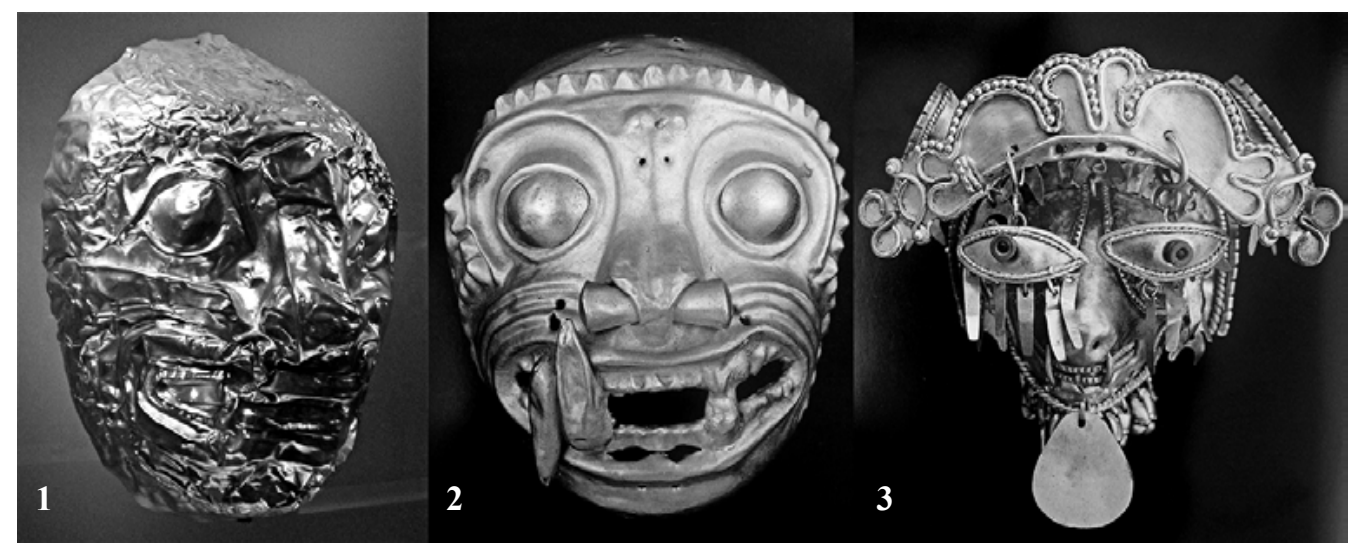

LÁmina 6. Máscaras rituales Tumaco y La Tolita. 1. Museo del Oro, Bogotá. 2 y 3 Museo Nacional del Banco Central del Ecuador, Quito.
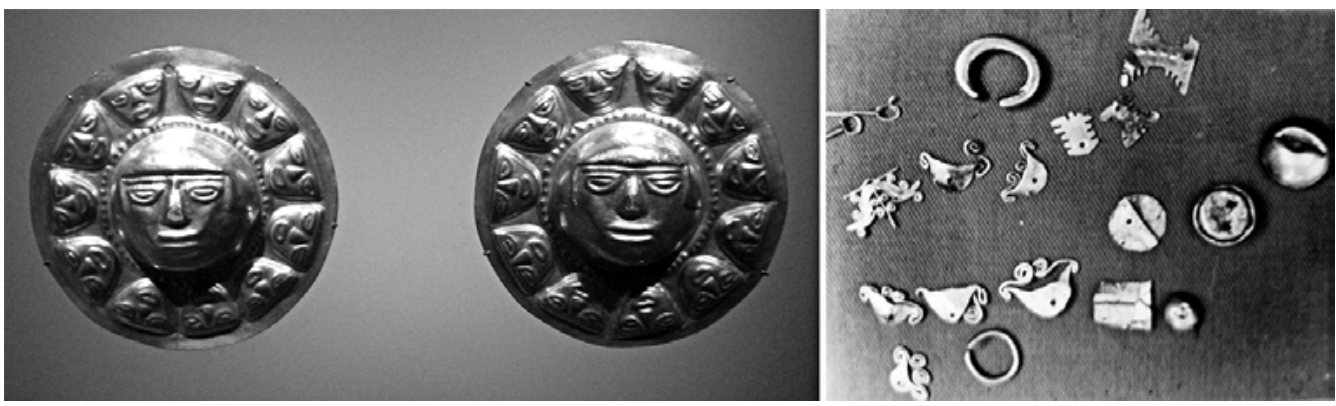

LÁmina 7. Orejeras y Piezas Ornamentales Orfebres. Museo del Oro, Bogotá 


\section{La vida cotidiana en el Tulato Costero}

Análisis de los asentamientos en la región revelan áreas de concentración de viviendas con montículos en zonas fluviales que tengan salidas a ríos, esteros, bocanas y mar abierto, lo que indica que hubo aprovechamiento de diversos recursos naturales de acuerdo con las zonas ecológicas ocupadas. Es evidente que durante el asentamiento más denso del Tulato, época de mucho florecimiento cultural, se ocuparon casi todas las áreas disponibles tanto, en el ecosistema de manglares y mar, abundante en pesca y recolección de moluscos, como en la llanura aluvial, rica en suelos fértiles y productos selváticos. Este aspecto sugiere que los habitantes tomaron ventaja máxima de los recursos medioambientales disponibles en los alrededores de los centros poblados. Los asentamientos también sugieren una complejidad en la distribución, estructura y función de estos espacios, casi siempre estaban bajo el poder de los caciques, que ocuparon los sitios más grandes y centralizados, anexos a las tierras y zonas agrícolas productivas (Lightfood, 1987; Patiño, 2003). Esto parece aplicarse a la distribución de los poblados en La Tolita, Inguapí, La Magnolia, La Catedral, Dos Quebradas y La Miranda en el río Mira. Estos sitios se circunscriben a áreas con extensas zonas de campos de cultivo prehispánicos, montículos centrales y satelitales, cuyos espacios entre ellos sirvieron como calles. Los sitios pequeños y dispersos parecen corresponder a lugares habitacionales de las gentes comunes, más dispersas pero conectadas al sistema en general.

Los asentamientos en los manglares sugieren pueblos palafitos, que aportaban abundantes recursos marinos (e.g., pesca, moluscos), además de ser especialistas en la navegación y estar conectados al intercambio regional. En los poblados principales las elites fueron capaces de movilizar individuos para trabajos considerables en la construcción de montículos. Estas estructuras parecen haber tenido una doble función: (1) para construcciones de edificaciones importantes, relacionadas con festividades, ritos y las residencias de sus gobernantes y, (2) para el enterramiento de sus gentes, como los observados en La Tolita, donde aparecen urnas y fosas que contienen diversos ajuares de conchas, metales y cerámicas (Valdez, 1987). Las casas en arcilla muestran una arquitectura basada en plantas cuadradas, rectangulares y circulares, con paredes en adobe y columnas en madera sosteniendo techos curvos con estructuras de madera a dos aguas, que recuerdan mucho las casas de la lejana Asía. Algunas de ellas están profusamente decoradas con diseños iconográficos geométricos, generalmente elaborados en las casas comunales destinadas a festividades y ritos chamánicos (Reichel-Dolmatoff, 1988; Wurster, 1989).
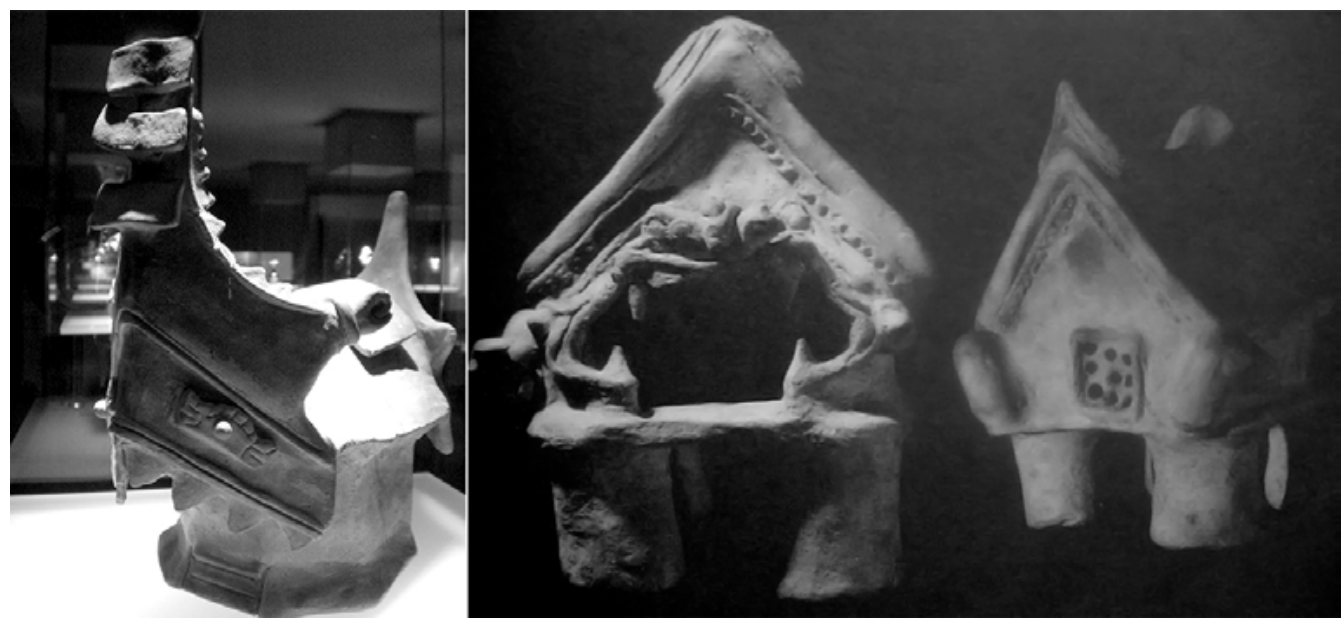

LÁmina 8. Moldes de Casas Ceremoniales Tumaco-Tolita. 1. Museo del Oro. Bogotá. 2. Wurster, 1989. 


\section{Agricultura intensiva, pesca, recolección y caza}

Uno de los hechos más destacados en las sociedades de rango es el manejo y control de los recursos de subsistencia, especialmente de las mejores tierras productivas, estas zonas generalmente son ocupadas por los centros de mayor poder económico y político (Drennan, 1996). Las sociedades del Tulato, de la misma manera que otras sociedades jerarquizadas lograron ocupar y adecuar las tierras más fértiles de la región para el desarrollo de una agricultura intensiva mediante la técnica de los camellones y canales. Su éxito obedeció a un eficaz control y organización sociopolítica por parte de las elites durante el auge y florecimiento de sus centros más destacados a lo largo de la costa, principalmente en áreas circunvecinas de La Tolita y Tumaco. Lo mismo podemos asegurar de otras áreas de Esmeraldas y de la provincia del Guayas donde se desarrollaron cacicazgos costeros similares (Stemper, 1993; Valdez, 1987; Zeidler y Pearsall, 1994).

Los estudios arqueológicos en el terreno evidencian que los antiguos campos de camellones cubrieron extensas áreas que alcanzan más de 100 hectáreas (e.g., Piñal Salado, -S06-). La ejecución de estos enormes trabajos agrarios sugiere una organizada movilización de mano de obra que buscaba, por un lado, poner en funcionamiento el sistema de camellones y drenajes y, por otro, suplir las necesidades de alimento de una sociedad en constante aumento poblacional. Estos campos trabajados con la técnica de camellones de cultivo en muchos casos sólo están parcialmente descubiertos, lo que indica que sus áreas son mayores y aún desconocidas. Los camellones se construyeron en las zonas más bajas de la llanura aluvial entre los 4 y 8 m.s.n.m., lo que los hace vulnerables a las inundaciones periódicas por mareas y por los ciclos anuales de invierno en la costa. Existen otros sitios, como La Tirsa (S59) y El Gran Cebú (S06) con campos que se localizan por encima de los 15 y 50 m.s.n.m. también en zonas planas inundables. Cerca de La Tolita se encuentran los campos agrícolas similares en La Laguna de la Ciudad. Durante la época del Tulato, es evidente que hubo incremento de la productividad agrícola con nuevas técnicas (e.g. camellones y drenajes) lo cual hizo posible soportar el aumento ostensible de la población y desde luego el tamaño de los asentamientos y sus redes de contacto (Lámina 9 y 10).

Estudios de polen, fitolitos y macrorestos en campos de cultivo prehispánico en Tumaco reportan la presencia de diversos cultígenos, entre los que se destacan: el maíz (Zea mays) en buena cantidad, calabaza (Curcubita), dos especies de palmas (Tagua y Chunga); conocieron tubérculos como la yuca (Manihot esculenta), presencia de maranta, aunque no se conoce si corresponde al arrowroot (Maranta arundinacea). A partir de la plástica de figurillas en arcilla se observa de manera indirecta otras plantas cultivadas relacionadas con el algodón (Gossypium barbadense) para tejido de prendas; la coca (Erythoroxilum) que aparece representada en muchos personajes mambeadores de Tumaco-Tolita (DeBoer, 1996; Patiño, 2003, 2006). En La Tolita, granos de maíz carbonizados fueron encontrados en asociación con instrumentos agrícolas (e.g., manos, metates y hachas trapezoides) datados cerca del 2.350 A.P. (Valdez, 1987). El transporte de los alimentos y otros productos se realizaba en canastos elaborados en fibras de palma; los vasos efigie conocidos como canasteros muestran esta actividad no sólo en Tumaco sino en todo el suroccidente de Colombia y norte del Ecuador; elemento que ha sido interpretado en favor de una gran actividad de intercambio a larga distancia entre la costa y la sierra Andina.

Antecedentes sobre la agricultura prehispánica han sido ampliamente reportados en las costas del Ecuador, especialmente en las regiones bajas inundables de las cuencas de los ríos Guayas, Daule y Babahoyo, donde se reconocen extensos campos de camellones como los de Samborondón, Peñón del Río (Durán), Taura y Colimes, entre otros (Parsons, 1973; Buys y Muse, 1987; Denevan y Mathewson, 1983; Stemper, 1993). Más al norte en la provincia de Esmeraldas evidencias de camellones aparecen al sur de la Isla de La Tolita (Montaño, 1990; Tihay y Usellman, 1995). En la zona andina del suroccidente colombiano también existen camellones que fueron usados durante el Período Yotoco (2000 A.P.), estos se ubican en el 


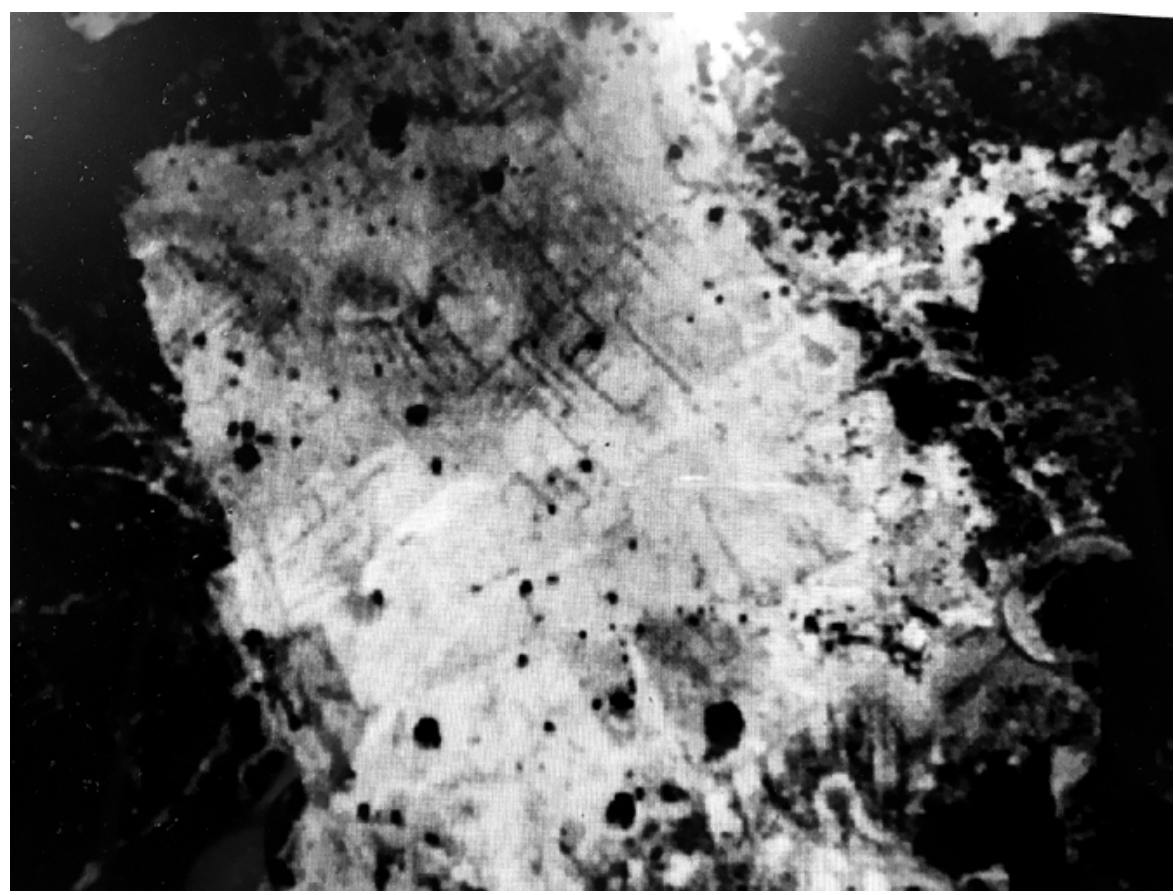

LÁmina 9. Zona Agraria. Piñal Salado (Tumaco). Foto Aérea IGAC Vuelo 2076, 1984.

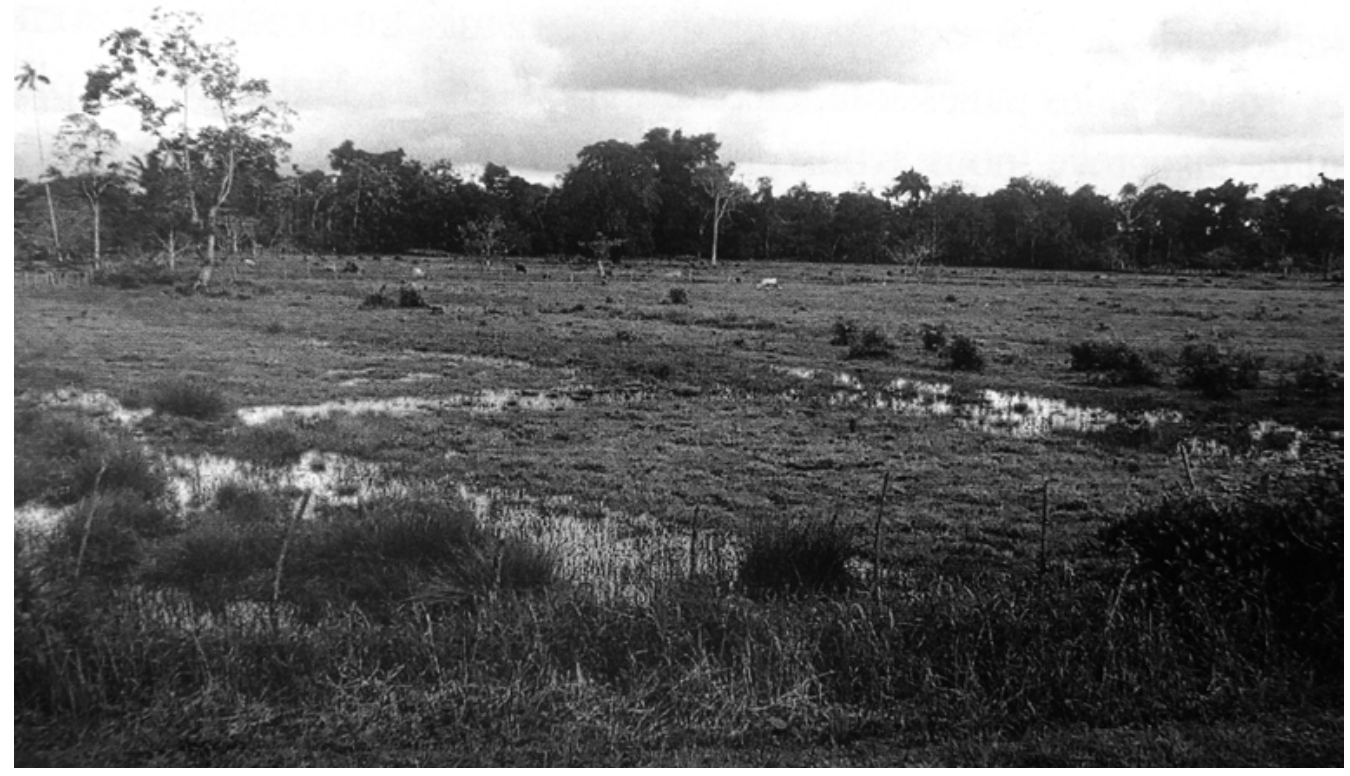

LÁmina 10. Drenajes y Camellones en Chilví-Inguapí. Foto J. F. Bouchard, 2003. 
fondo plano e inundable del valle de El Dorado, Calima (Cordillera Occidental) (Cardale et al. 1992). Al norte de Colombia, la zona del bajo San Jorge en las llanuras del Caribe, se destacan extensos campos de cultivo prehispánicos, los trabajos en camellones se encuentran en más de 500.000 hectáreas pantanosas. La época que registra más densidad poblacional (plataformas, túmulos funerarios) y mayor construcción de los sistemas de camellones se establece entre el 2.150 A.P. y 1.500 A.P. En la historia paleoclimática de la región esta época corresponde a una de mayor humedad (Plazas et al., 1993).

En la economía de las sociedades costeras, no hay duda de que ésta estuvo basada en la agricultura; pero también fue muy importante la pesca artesanal. Se ha sostenido que el maíz, complementado con una dieta marina, sirvió de base alimenticia sólida en el incremento demográfico de sociedades agrarias costeras (Raymond et al., 1993). Es probable que los canales que regulaban las aguas en los campos de cultivo también se aprovecharon para la cría de peces, tal como se sugiere para otros sitios arqueológicos (Erickson, 1995). De otro lado, la pesca artesanal tanto en bocanas, esteros y mar abierto fue altamente productiva gracias a la diversidad ictiológica. Estudiar este tipo de dietas en Tumaco es problemático ya que los restos de peces y otras especies no se conservan en los yacimientos arqueológicos, lo que dificulta inferir de manera directa el papel de la pesca en la dieta de estos grupos costeros. En manglares y esteros abundan recursos terrestres y marinos, éstos se extiende tierra adentro hasta unos $10 \mathrm{~km}$. formando una red fluvial de aguas saladas y dulces afectadas por las mareas. En estas zonas las fuentes de subsistencia son identificadas a partir de los restos arqueológicos cerámicos y líticos. Los típicos ralladores de arcilla con incrustaciones de microlitos fueron utilizados para varios fines, especialmente en la preparación de peces y el rallado de alimentos como la yuca (DeBoer, 1996; Ciudad, 1984).

En mar abierto y estuarios, la pesca y recolección de mariscos fueron actividades complementarias de la dieta de estas sociedades. Un sin número de pesas de red líticas son encontradas en sitios de manglares y al interior de los sistemas fluviales. R. Cooke (1992) ha sostenido que la pesca artesanal en estuarios debió ser relativamente fácil mediante el uso de pequeñas canoas, redes con pesas de piedra y anzuelos puestos en línea. También debió ser importante el conocimiento regional del comportamiento y hábito de las especies marinas y deltaicas. De otra manera, pescar en aguas profundas requeriría de equipos más complejos y de una mayor tecnología que pescar en aguas bajas influenciadas por mareas. Las rutas marinas, los esteros y los ríos sirvieron de caminos naturales de comunicación entre los poblados Tumaco-Tolita que distribuyeron a lo largo de la costa por cientos de kilómetros, a su vez estas rutas fueron usadas para extender las redes de intercambio de productos e ideas, entre las mismas zonas costeras y las regiones interiores andinas más lejanas.

\section{Redes de intercambio y bienes}

Para la época del Tulato la costa Pacífica proveyó innumerables recursos de subsistencia, así como materias primas para realizar productos de diferente índole (e.g., personales, suntuarios y rituales, entre otros), este aspecto debió generar excedentes que dieron paso a una importante movilidad de bienes dentro de la región y hacia un intercambio entre localidades costeras y otros pueblos de regiones altoandinas. Las relaciones de intercambio desde y hacia la región Tumaco-Tolita se pueden establecer desde dos rutas: (1) la costera donde se comerciaban objetos suntuarios tales como cuentas de piedra, conchas (Spondylus sp., Strombus), alucinógenos (coca) y metales (oro, platino) y, (2) las rutas interiores andinas, a donde se llevaba oro, piedras, maderas (chonta), sal y coca principalmente. De las zonas andinas al menos un producto se reconoce dentro de esta red y se trata de tráfico de obsidianas. La red en su conjunto nos indica que los interesados en el intercambio accedían a un variado 
$\mathrm{y}$ amplio número de productos y materias primas. Algunos de estos elementos pudieron haber sido usados como bienes de prestigio por las elites, lo cual se constituye en una característica importante de las sociedades de rango (Deboer, 1996; Drennan, 1995; Gnecco, 1998; Salazar, 1992; Zeidler, 1994).

La obsidiana es un material volcánico andino que se intercambió con productos de tierras bajas costeras gracias al estímulo y demanda de las sociedades complejas de ambas regiones. En el norte del Ecuador podemos esbozar, según evidencias arqueológicas, posibles rutas de intercambio entre la sierra y las costas de Esmeraldas y Tumaco. Evidencias de intercambio se observan entre las regiones de Tumaco-Tolita y el este de Quito, en el sitio Jardín del Este, zona cercana a las fuentes principales de obsidiana. (Cf. Buys y Domínguez, 1989; De Paepe y Buys, 1990).

\section{La decadencia del Tulato. Otros desarrollos culturales costeros}

A partir del 1.650 A.P. en la región de Tumaco y vecindades se experimentan cambios culturales que parecen revelar la crisis en las estructuras cacicales del Tulato. Los grandes avances culturales y tecnológicos de estas sociedades dejan de percibirse, para dar paso a diferentes manifestaciones culturales en la isla de El Morro y zonas aluviales y fluviales interiores. Para esa época ya no se construyen montículos artificiales, no se trabaja la tierra con camellones y canales, ni tampoco se produce la alfarería y figurillas características de sociedades Tumaco-Tolita. Los grupos tardíos en Tumaco están representados por gentes Bucheli-Caunapí, quienes se asentaron en las tierras bajas selváticas. La alfarería que caracteriza a estos grupos es sencilla y en algunos casos rústica, con ollas globulares y subglobulares, cuencos simples, hemisféricos y aquillados. La decoración presenta motivos geométricos incisos en la parte superior de los recipientes (Cf. Bouchard, 1982-83; Patiño, 2003). También está presente la pintura roja en el labio de los recipientes; la aplicación de tiras decoradas, y la representación esquemática de figuras antropomorfas. La mayoría de las formas fueron elaboradas para su uso en la cocina, aunque se percibe que algunas vasijas de tamaño mayor fueron utilizadas para entierros secundarios, una práctica bastante difundida entre los grupos tardíos de la llanura costera y partes serranas andinas. El tamaño de los poblados no fue muy grande y sus viviendas se dispersaron a lo largo de los ríos ocupando un hábitat de selva tropical húmeda. Teniendo en cuenta la distribución de los asentamientos, podemos establecer que los recursos económicos de estos grupos estarían basados en una agricultura probablemente de roza y quema, donde el maíz (Zea mays) y la yuca (Manihoc esculenta) serían los principales productos. Las actividades de recolección, pesca y caza en los ecosistemas llanura selvática jugaron un papel importante en la economía de estos grupos.

En términos de complejidad social los grupos Bucheli-Caunapí podrían haber alcanzado un estado tribal con clanes igualitarios dirigidos por líderes locales o jefes que pudieron ser los mismos chamanes, los cuales tomaban decisiones de grupo y dirigían las ceremonias que regulaban la estabilidad social, económica y política (Johnson y Earle, 1987: 160). Obviamente esta organización social en nada se compara con aquellas erigidas en épocas anteriores en el litoral Pacífico del sur de Colombia y norte del Ecuador. las evidencias arqueológicas se correlacionan con sociedades igualitarias (tribales) que ocupan poblados nucleados pequeños con viviendas dispersas en áreas reducidas, así mismo, los enterramientos son simples y en muchos casos no contienen ajuar funerario; los objetos de cerámica y orfebrería son elaborados de manera sencilla y, por último, el intercambio entre grupos es limitado y su influencia máxima alcanza de forma transversal contactos con sociedades del occidente andino, como en el caso de los grupos del altiplano nariñense y aquellos del alto valle del Patía y Guachicono (Patiño, 1990; Uribe, 1976, 1986). 


\section{El patrimonio arqueológico en la costa pacífica}

En futuras investigaciones debemos concentrarnos en el surgimiento y cristalización de los sistemas de intercambio, así como su importancia regional costa-sierra en el origen y desarrollo de los centros Tumaco-Tolita. Se debe profundizar sobre el mecanismo en el circuito del intercambio, los sitios de abastecimiento (flujos), obtención de las materias primas, formas de transporte, mercaderes y puntos de contacto a través de los valles y sierras andinas. A lo largo de la costa también debemos profundizar sobre el control y circulación de los productos de intercambio ya sea por vía marítima o terrestre. Igualmente, ser rigurosos en el registro de objetos de intercambio ya sea que estos se relacionen con la economía de productos alimenticios o de bienes suntuarios.

Las sociedades del Tulato incluyeron dentro de sus bienes suntuarios los trabajos en metal, desafortunadamente muchos de los sitios arqueológicos del área de Esmeraldas y Tumaco han sido y continúan siendo objeto de la guaquería, aspecto que ha limitado el desarrollo de estudios completos para el área. Por el momento no es posible llevar a cabo un análisis íntegro de la metalurgia de la zona ya que solamente contamos con unos cuantos hallazgos sistemáticos, un mayor número de análisis metalográficos y pocas fechas de C-14 confiables; todo esto en comparación con la gran masa de objetos arqueológicos, generalmente sin contexto alguno, diseminados en colecciones particulares y museos. Es cierto que podemos estudiar los aspectos tecnológicos formales de los metales y en algunos casos inferir su uso y simbología de acuerdo con el pensamiento de las comunidades indígenas. Sin embargo, para nuestras inferencias e interpretaciones, el contexto arqueológico en que se presentan los restos arqueológicos es de vital importancia. En la actualidad la región de Tumaco se encuentra en plena expansión urbana e industrial, sin embargo, no se observan planes locales donde se desarrollen programas de arqueología preventiva o planes de manejo arqueológico que mitiguen la pérdida del patrimonio cultural arqueológico. 


\section{Bibliografía}

Barona, Guido. 2004, El Combate de las Morales, Editorial Universidad del Cauca, Popayán.

Bouchard, J. F. y P. Usselmann. 2003, Trois Millénaires de Civilisation entre Colombie et Équateur. CNRS Editions. Paris.

Brumfiel, E. M. y T. K. Earle. 1987, "Specialization, exchange, and complex societies: an introduction”, en: E.M. Brumfiel y T.K. Earle (Eds.) Specialization, Exchange, and Complex Societies, Cambridge University Press, Cambridge, pp. 1-9.

Buys, J. E. y M. Muse. 1987, “Arqueología de asentamientos asociados a los campos elevados de Peñón del Río, Guayas, Ecuador", en: Denevan, W.M. et al. (Eds.) Prehispanic agricultural fields in the andean region: part $i$, BAR International Series 359(i), Oxford.

Cardale, M. et al. 1992, Calima: Diez mil años de Historia en el Suroccidente de Colombia, Fundación Pro-Calima, Editorial Printer Colombiana, Ltda., Bogotá.

Currie, E. 1993, “Archaeology, ethnohistory and exchange along the coast of Ecuador”, en: Antiquity 69, pp. 511-526.

DeBoer, W. 1996, Traces behind the Esmeraldas Shore: Prehistory of the Santiago-Cayapas Region, Ecuador, The University of Alabama Press, Alabama.

1975, "The Archaeological Evidence for Manioc Cultivation", en: American Antiquity 40(4), pp. 419-432.

Denevan, W. y K. Mathewson. 1982, "Preliminary results of the Samborondon raised field project, Guayas Basin, Ecuador", en: Darch J. P. (Ed.) Drained Field Agriculture in central and South America, BAR International Series 189, pp. 167-182.

De Paepe, P. y J. Buys. 1990, “Análisis mineralógico y químico de la cerámica procedente del sitio arqueológico "Jardín del Este”, Cumbayá, Provincia de Pichincha, Ecuador”, en: Gaceta Arqueológica Andina 5(20), pp.5-18.

Drennan, R. 1996, "Betwixt and between in the Intermediate Area", en: Journal of Archaeological Research 4(2), pp. 95-132.

1995, "Chiefdoms in Northern South America", en: Journal of World Prehistory 9(3), pp. 301-340.

1991, "Prehispanic Chiefdom Trajectories in Mesoamerica, Central America, and Northern South America", en: Earle T. (Ed.) Chiefdoms: Power, Economy, and Ideology, Cambridge University Press, Cambridge, pp. 263-287.

Duncan, R. 1944, “Arte Tumaco-Tolita: Iconografía de la Figura Humana”, en: América Negra (7), pp.103-118.

Earle, T. K. (Ed.). 1991, Chiefdoms: Power, Economy, and Ideology, Cambridge University Press, Cambridge.

Erickson, C. 1995, "Archaeological methods for the study of ancient landscapes of the Llanos de Mojos in the Bolivian Amazon”, en: Stahl P. (Ed.) Archaeology in the Lowland American Tropics, Cambridge University, Cambridge, pp. 66-95.

Errázuriz, J. 1980, Tumaco-La Tolita. Una Cultura Precolombina Desconocida, Carlos Valencia, Bogotá.

Feldman, R. 1987, "Architectural evidence for the development of nonegalitarian social systems in coastal Peru”, en: Haas J. et al. (Eds.) The Origins and Development of the Andean State, Cambridge University Press, Cambridge , pp. 9-14.

Fried, M. 1967, The Evolution of Political Society: An essay in political anthropology, Random House, New York.

Gnecco, C. 1998, "El Poder en las Sociedades Prehispánicas de Colombia: Un Ensayo de Interpretación”, en: El Poder en Escena. Colombia Prehispánica,Banco de la República, INAH, Ministerio de Cultura, Bogotá, pp. 17-48.

1995, "Relaciones de intercambio y bienes de elite entre los cacicazgos del suroccidente de Colombia", en: Langebaek C. y F. Cárdenas (Eds.). Caciques, Intercambio y poder: Interacción Regional en el Área Intermedia de las Américas, Universidad de Los Andes, Bogotá pp. 175-196.

Guinea, M. 1995, “Ecología y cultura en el área de la desembocadura del rio Esmeraldas, Ecuador”, en: Guinea, Mercedes et al. (Eds.) Cultura y Medio Ambiente en el Área Andina Septentrional, Editorial Abya-Yala 21, Quito, pp.165-194.

Lightfood, K. 1987, “A consideration of complex prehistoric societies in the U.S. Southwest”, en: Drennan R. y C. Uribe (Eds.) Chiefdoms in the Americas, University Press of America, Lanham, pp.307-323.

Montaño, M. C.1990, "El Manejo de los Recursos Naturales en la Tolita en su Etapa Clásica”, Presentado al Encuentro Ecuantoriano-Colombiano de Culturas Comunes, Comisión de vecindad Ecuatoriano-Colombiano, Banco Central del Ecuador, Esmeraldas, 12-16 Nov, 1990.

Patiño, D. 2006 "Campos prehispánicos elevados en la economía Tumaco-La Tolita, Costa Pacífica de Colombia”, en: Valdez, Francisco (Ed.) Agricultura Ancestral, Camellones y Albarradas; IFEA, Abya Yala, Banco Central del Ecuador, IRD, CNRS, INPC, Quito, pp.69-188.

2003, Tumaco Prehispánico: Asentamiento, Subsistencia e Intercambio en la Costa Pacífica de Colombia, Editorial Universidad del Cauca, Popayán.

1990, "Pobladores Prehispánicos del Cauca, Colombia", Informes Antropológicos 4, Icanh, pp. 35-52.

1988, Asentamientos Prehispánicos en la Costa Pacífica Caucana, Fundación de Investigaciones Arqueológicas Nacionales, Banco de la República. Bogotá. 
Parsons, J. 1973, "Campos de cultivos prehispánicos con camellones paralelos, en la cuenca del río Guayas, Ecuador" en: Cuadernos de Historia y Arqueología (40), pp.185-202.

Plazas, C. y A. M. Falchetti. 1986, "Patrones culturales en la orfebrería prehispánica de Colombia", en: Metalurgia de América Precolombina, Colección Bibliográfica Banco de la República. Bogotá, pp. 203-227.

Plazas, C. et al. 1993, La sociedad hidráulica Zenú: estudio arqueológico de 2000 años de historia en las llanuras del caribe colombiano, Banco de La República, Bogotá.

Raymond, S et al. 1993, "Staple foods in Formative Coastal Ecuador: Maize, Manioc, Fish?", paper presented in Tropical Coastal Subsistence symposium at the 58th Annual Meeting of the Society for American Archaeology, April 14-18, St. Louis, Missouri.

Reichel-Dolmatoff, G. 1988, Orfebreria y Chamanismo. Un estudio iconográfico del Museo del Oro, Editorial Colina, Medellín.

1986, Arqueología de Colombia: Un texto introductorio, Fundación Segunda Expedición Botánica, Litografía Arco, Bogotá.

Romoli de Avery, Kathleen. 1963, “Apuntes sobre los pueblos autóctonos del litoral colombiano del Pacífico en la época de la conquista española", en: Revista Colombiana de Antropología 12, Bogotá, pp. 260-292.

Salazar, E. 1992, "El intercambio de obsidiana en el Ecuador precolombino: perspectivas teorico-metodológicas", en: Politis G. (Ed.) Arqueología en América Latina hoy, Biblioteca Banco Popular, Bogotá, pp. 116-131.

Stemper, D. 1993, The persistence of prehispanic chiefdoms on the Río Daule, Coastal Ecuador, University of Pittsburgh Memoirs in Latin American Archaeology No.7, pp.169-180.

Tihay, J. P. y P. Usselmann. 1995, "Medio ambiente y ocupación humana en el litoral Pacífico Colombo-ecuatoriano", en: Guinea, M. et al. (Eds) Cultura y Medio Ambiente en el Área Andina Septentrional, Biblioteca Abya-Yala 21, Quito, pp. 377-399.

Ugalde, María Fernanda. 2009, Iconografia de la Cultura Tolita. FAAK 7, Reichert Verlag, Wiesbaden, Alemania.

Valdez, F. 1987, Proyecto arqueológico La Tolita (1983-86), Museo del Banco Central del Ecuador, Editorial Luz de América, Quito.

Wurster, Wolfgang. 1989, "Representaciones arquitectónicas del Ecuador Prehispánico", en: Moreno, Segundo E. (Comp.) Antropología del Ecuador. Memorias del primer simposio europeo sobre antropología del Ecuador, 8, Abya Yala, Quito. pp. 61-78. 